\title{
Identifying responders and nonresponders to interferon therapy in multiple sclerosis
}

This article was published in the following Dove Press journal:

Degenerative Neurological and Neuromuscular Disease

I April 2014

Number of times this article has been viewed

\section{Luca Prosperini' \\ Marco Capobianco ${ }^{2}$ \\ Costanza Gianni ${ }^{3}$ \\ 'Department of Neurology and Psychiatry, Sapienza University, Rome, Italy; ${ }^{2}$ Regional Multiple Sclerosis Centre, University Hospital San Luigi Gonzaga, Orbassano, Italy; ${ }^{3}$ Martinos Center for Biomedical Imaging, Massachusetts General Hospital, Boston, MA, USA}

\begin{abstract}
Interferon beta is a well established disease-modifying agent used for relapsing-remitting multiple sclerosis. Despite treatment, a relevant proportion of patients continue to experience clinical (ie, relapses, worsening of disability) and magnetic resonance imaging (MRI) activity. Early identification of responders and nonresponders to interferon beta is strongly recommended to select patients who need a prompt switch to another diseasemodifying agent and to ultimately avoid accumulation of fixed disability over time. Detecting responders and nonresponders to interferon beta can be challenging, mainly because of the lack of a clear and shared clinical definition of response to treatment. Clinical features at the start of treatment should be considered as prognostic factors, but MRI parameters assessed during treatment, such as contrast-enhancing lesions or new T2-hyperintense lesions, may be sensitive markers of response to interferon beta. Quantitative scoring systems derived from a combination of relapses and MRI activity have recently been proposed as practical tools for use in the everyday clinical setting. Blood biomarkers, such as neutralizing antibodies to interferon beta and Myxovirus resistance protein A, provide further useful information for detecting responders and nonresponders to interferon beta. However, since the presence of neutralizing antibodies can only partially explain the nonresponse to interferon beta, biomarkers of interferon beta activity possibly related to the pathogenesis of the disease could represent a future step toward a tailored, long-lasting effective treatment against multiple sclerosis.
\end{abstract}

Keywords: interferon beta, responders, nonresponders, multiple sclerosis

\section{Introduction}

Multiple sclerosis is a lifelong demyelinating disease typically affecting young adults. It is widely believed to be an autoimmune disorder triggered by environmental factors in genetically predisposed subjects. ${ }^{1}$ The clinical onset of multiple sclerosis tends to be between 15 and 50 years of age, with a female predominance at a ratio of 2-3:1 over males. $^{2}$

Symptomatic treatment has been the mainstay of treatment for patients with multiple sclerosis. ${ }^{3}$ However, in the last decade, improved diagnostic criteria and availability of effective therapies have led to a paradigm shift toward earlier diagnosis and treatment. ${ }^{4}$

Ten disease-modifying agents are now approved for the treatment of patients with multiple sclerosis: three formulations of interferon beta (IFNB), including subcutaneous IFNB-1b $250 \mu \mathrm{g}$ every other day (Betaseron ${ }^{\circledR}$; Bayer, Whippany, NJ, USA, and Schering, Milton Keynes, UK), intramuscular IFNB-1a $30 \mu \mathrm{g}$ once weekly (Avonex $^{\circledR}$; Biogen Idec, Cambridge, MA, USA), and subcutaneous IFNB-1a $22 \mu \mathrm{g}$ or
Correspondence: Luca Prosperini Department of Neurology and Psychiatry, Sapienza University, Viale dell'Università 30, Rome 00185 , Italy Tel +39649914716

Fax +39633775900

Email luca.prosperini@uniromal.it 
$44 \mu \mathrm{g}$ three times per week (Rebif ${ }^{\mathbb{B}}$; Merck Serono, Geneva, Switzerland); subcutaneous glatiramer acetate $20 \mathrm{mg}$ once a day (Copaxone ${ }^{\circledR}$; Teva, Petach Tikva, Israel); an immunosuppressive agent, mitoxantrone (Novantrone ${ }^{\circledR}$; Wyeth, Maidenhead, UK); a monoclonal antibody, natalizumab (Tysabri ${ }^{\circledR}$; Biogen Idec); and three oral drugs, ie, fingolimod $0.5 \mathrm{mg}$ once a day (Gilenya ${ }^{\circledR}$; Novartis, Basel, Switzerland), teriflunomide $14 \mathrm{mg}$ once a day (Aubagio ${ }^{\circledR}$; Genzyme, Cambridge, MA, USA), and dimethyl fumarate (Tecfidera ${ }^{\circledR}$; Biogen Idec).

Despite the increasing availability of new disease-modifying agents, IFNB formulations still remain the standard of care for patients with multiple sclerosis. Phase III randomized controlled trials (RCTs) have consistently shown that IFNB is effective in reducing the relapse rate and new demyelinating lesions as seen on magnetic resonance imaging (MRI). It is also extensively documented that IFNB slows progression of disability when compared with placebo..$^{5-10}$ Extension phases of original RCTs and post-marketing studies have confirmed early reports of persistent clinical and MRI efficacy over time. ${ }^{11-16}$ Moreover, prolonged survival has recently been observed in patients who initially received IFNB-1b treatment compared with those originally randomized to placebo. ${ }^{17}$ Lastly, the available data from RCTs indicate that IFNB is most effective when started early, even in subjects presenting a clinically isolated syndrome suggestive of multiple sclerosis. ${ }^{18-21}$ However, response to IFNB is largely heterogeneous, and a significant number of IFNB-treated subjects continue to experience clinical and MRI disease activity despite treatment. ${ }^{22}$ Therefore, early identification of patients with a poor response to IFNB and a prompt switch to another disease-modifying agent (if necessary) are required in order to avoid relapses and accumulation of fixed disability over time. ${ }^{23}$

In this review, we summarize the studies that have investigated response and nonresponse to IFNB as a treatment for multiple sclerosis. Studies that merged data of patients treated with IFNB and glatiramer acetate were not included.

\section{Definition of response or nonresponse to IFNB}

A major difficulty in identifying responders and nonresponders to IFNB is that a clear and shared clinical definition of a poor/absent response to IFNB does not exist. ${ }^{22,24}$ The definition of response to treatment is commonly based on two fundamental features of multiple sclerosis, ie, relapses and progression of disability (or a combination of both).

Regarding relapses, different definitions of response to IFNB have been used, including frequency and severity of clinical exacerbations, reduction in relapse rate when compared with pretreatment period, number of patients remaining relapse-free, and degree of recovery after an acute inflammatory event. ${ }^{25}$ There are some concerns when clinical criteria based on relapses are adopted to define response and nonresponse to IFNB. First, the relapse rate is influenced by the phenomenon of regression to the mean, which may represent a confounding factor. Second, the clinical severity of a relapse depends on the location of focal demyelinating inflammation in the central nervous system. Third, incomplete recovery after a clinical exacerbation may reflect an individual pathological pattern of disease activity rather than the pattern of response to treatment. Lastly, excluding pseudoexacerbations is not always possible.

Several authors have identified worsening disability as the key indicator of the long-term efficacy of a disease-modifying agent. Criteria for response to IFNB based on assessment of disability have been found more sensitive and more specific in predicting long-term disability. ${ }^{26}$ Progression of disability may be defined in different ways, eg, as a sustained increase in Expanded Disability Status Scale (EDSS) score, ${ }^{27}$ time to shift to a secondary progressive course, time to reach EDSS milestones of 4.0 or 6.0 , or even changes in the multiple sclerosis functional composite score. ${ }^{28}$ However, a sustained increase of 1.0 or more in EDSS points that persists for at least two consecutive scheduled visits separated by a 6-month interval is widely accepted as an accurate indicator of lack of response to a disease-modifying agent. ${ }^{29}$

\section{Baseline clinical features identifying responders and nonresponders to IFNB}

Randomized controlled trials have failed to identify any baseline features, other than the arm assignment, associated with response to IFNB. Further, post-marketing studies designed to assess this issue have generally included shortterm follow-up (2-4 years), used different criteria for defining response/nonresponse to IFNB, and yielded conflicting results (Table 1) ${ }^{30-38}$ In this regard, it has been suggested that the assumption of an "a priori" criterion strongly influences both the proportions of responders and nonresponders and the potential predictors of response and nonresponse to IFNB. ${ }^{26,34}$ The regression to the mean phenomenon may occur when relapses are considered as either a response outcome or as potential predictor of response to IFNB. Several studies have found an association between a worse EDSS score and lack of response to IFNB; however, higher early EDSS scores can also be considered a marker of an adverse prognosis, regardless of the disease-modifying agent received by patients. 
In conclusion, pre-IFNB clinical characteristics, such as disease duration, EDSS score, and relapse rate prior to starting IFNB should be considered as prognostic factors rather than as markers of response to treatment. ${ }^{24}$

\section{On-treatment MRI features as a marker of response or nonresponse to IFNB}

Conventional MRI is a powerful tool for monitoring the pathological processes involved in multiple sclerosis. New active lesions on MRI are about 5-10 times more frequent than clinical relapses, especially in patients with a relapsingremitting course of multiple sclerosis. ${ }^{39}$

The concept of monitoring the biological effect of IFNB by MRI is based on the drug's mechanism of action. In fact, although IFNB is a pleiotropic cytokine exerting complex effects, one of its most important actions involves control of the blood-brain barrier. ${ }^{40}$ Therefore, persistence of the inflammatory components of the disease, ie, contrast enhancing lesions or new/enlarged T2-hyperintense lesions, might suggest a lack of biological effect of IFNB, even when the disease is clinically silent.

A post hoc analysis of the original RCT of intramuscular IFNB-1a found worse disability outcomes in patients who had relapses during 2-year follow-up, but no differences were observed between the active group and the placebo group. ${ }^{41}$ In contrast, accumulation of more than two new or enlarged T2-hyperintense lesions during the study was associated with poor disability outcome in the active treatment group but not in the placebo group. ${ }^{41}$ This latter finding supports the use of MRI as a marker of response to IFNB rather than as a prognostic tool.

Several independent, observational, post-marketing studies confirmed that an MRI scan, performed after 6-12 months of IFNB treatment, is able to predict a subsequent lack of response to IFNB even in the absence of clinical activity

Table I Summary of studies investigating baseline demographic and clinical characteristics associated with response and nonresponse to IFNB in patients with multiple sclerosis

\begin{tabular}{|c|c|c|c|c|c|}
\hline Study & $\begin{array}{l}\text { Sample } \\
\text { size }\end{array}$ & $\begin{array}{l}\text { Follow-up } \\
\text { (years) }\end{array}$ & Definition of nonresponse & Nonresponders & $\begin{array}{l}\text { Baseline features associated } \\
\text { with poor response }\end{array}$ \\
\hline \multirow[t]{4}{*}{ Roullet et $\mathrm{al}^{30}$} & 116 & 2 & Any relapse & $67 \%$ & Higher pre-IFNB relapse rate \\
\hline & & & $\begin{array}{l}\text { No relapse rate reduction with } \\
\text { respect to pre-IFNB period }\end{array}$ & $33 \%$ & Lower pre-IFNB relapse rate \\
\hline & & & $\begin{array}{l}\text { Any relapse and one-point } \\
\text { EDSS progression }\end{array}$ & $27 \%$ & Higher pre-IFNB relapse rate \\
\hline & & & $\begin{array}{l}\text { No relapse rate reduction with } \\
\text { respect to pre-IFNB period and } \\
\text { one-point EDSS progression }\end{array}$ & $34 \%$ & - \\
\hline Waubant et $\mathrm{al}^{31}$ & 200 & 2 & $\begin{array}{l}\text { No relapse rate reduction with } \\
\text { respect to pre-IFNB period }\end{array}$ & $32 \%$ & $\begin{array}{l}\text { Younger age } \\
\text { Shorter disease duration } \\
\text { Lower pre-IFNB relapse rate }\end{array}$ \\
\hline Trojano et $\mathrm{al}^{32}$ & 378 & 2 & $\begin{array}{l}\text { No relapse rate reduction with } \\
\text { respect to pre-IFNB period }\end{array}$ & $60 \%$ & $\begin{array}{l}\text { Longer disease duration } \\
\text { Lower pre-IFNB relapse rate }\end{array}$ \\
\hline \multirow[t]{2}{*}{ Coppola et al ${ }^{33}$} & 153 & 3 & Any relapse & $60 \%$ & $\begin{array}{l}\geq 2 \text { relapses in the } \\
\text { pre-IFNB period }\end{array}$ \\
\hline & & & One-point EDSS progression & $42 \%$ & EDSS score of $\geq 2.0$ \\
\hline \multirow[t]{4}{*}{ Portaccio et $\mathrm{al}^{34}$} & 147 & 2 & $\begin{array}{l}\text { No relapse rate reduction with } \\
\text { respect to pre-IFNB period }\end{array}$ & $28 \%$ & Lower pre-IFNB relapse rate \\
\hline & & & $\begin{array}{l}\text { Less than } 30 \% \text { relapse rate reduction } \\
\text { with respect to pre-IFNB period }\end{array}$ & $27 \%$ & Lower pre-IFNB relapse rate \\
\hline & & & Any relapse & $56 \%$ & Higher pre-IFNB relapse rate \\
\hline & & & One-point EDSS progression & $27 \%$ & None \\
\hline O'Rourke et $\mathrm{al}^{35}$ & 175 & 5 & One-point EDSS progression & $34 \%$ & Higher EDSS score \\
\hline Fromont et al ${ }^{36}$ & 751 & 2 & $\begin{array}{l}\text { No relapse rate reduction with } \\
\text { respect to pre-IFNB period }\end{array}$ & $28 \%$ & $\begin{array}{l}\text { Monosymptomatic onset } \\
\text { Younger age } \\
\text { Lower pre-IFNB relapse rate }\end{array}$ \\
\hline Goodin et $\mathrm{al}^{37}$ & 260 & 16 & $\begin{array}{l}\text { Shift to SP course or EDSS } \\
\text { score } \geq 6.0\end{array}$ & $54 \%$ & $\begin{array}{l}\text { Higher EDSS score } \\
\text { Male sex }\end{array}$ \\
\hline Mezei et $\mathrm{a}^{38}$ & 81 & 4.5 & $\begin{array}{l}\text { No relapse rate reduction with } \\
\text { respect to pre-IFNB period }\end{array}$ & $28 \%$ & Longer disease duration \\
\hline
\end{tabular}

Abbreviations: IFNB, interferon beta; EDSS, Expanded Disability Status Scale; SP, secondary progressive. 
on treatment, and irrespective of the definition of treatment response used (Table 2 ). ${ }^{42-48}$

Disease activity as seen on MRI has been reported as a valid surrogate marker for clinical activity. ${ }^{49-51} \mathrm{~A}$ post hoc analysis combining data from two RCTs of subcutaneous IFNB-1a showed that treatment effect on new T2hyperintense lesions after the first year of treatment accounted for a significant proportion of treatment effect on relapses over the subsequent year. ${ }^{50}$

It was recently reported that four-year clinical outcomes in IFNB-treated patients fulfilling the European Medicine Agency criteria for escalating to second-line diseasemodifying agents, ie, one or more relapses and either $\geq 9$ T2-hyperintense lesions on brain MRI or one or more contrast enhancing lesions after 1 year of treatment with IFNB, did not differ from those shown to have isolated MRI activity at the 1-year scan, defined as the presence of at least one contrast enhancing lesion or two or more new T2 lesions. ${ }^{52}$ This study suggests that on-treatment MRI monitoring is more sensitive than composite scores for early prediction of nonresponse to IFNB. Lastly, a "dose-effect" with regard to new MRI lesions has also been described, ie, the greater the number of new T2-hyperintense lesions detected after the first year of IFNB treatment, the higher the risk of subsequent accumulation of disability. This finding was replicated even after considering only patients who remained stable (ie, relapse-free) in the first year of IFNB therapy (Figure 1). ${ }^{45}$

\section{Composite scores to identify response and nonresponse to IFNB}

Some investigators still consider that isolated MRI activity is not sufficient to determine IFNB failure, and have proposed composite scores based on integration of different parameters of disease activity to identify response and nonresponse to IFNB treatment. ${ }^{24,53-55}$ This latter suggestion is based on evidence that the effect of treatment on the combination of MRI activity and relapses in the first year accounts for almost $100 \%$ of the effect of treatment on progression of disability at 2 years. ${ }^{56}$

The Canadian MS Working Group has updated its recommendations to neurologists for optimal use of disease-modifying agents. ${ }^{57}$ While these consensus recommendations were based on a qualitative analogic model that takes into account relapses, disability, and MRI features during treatment, other groups have designed quantitative scoring systems based on combinations of clinical and radiological disease activity. ${ }^{53,54}$ The seminal paper suggested that only the concomitant presence of at least two parameters (relapses, progression of disability, activity on MRI) in the first year of treatment with IFNB has significant value for identifying nonresponders in the subsequent 2 years. ${ }^{53}$

This scoring system was recently refined on the basis of a reanalysis of the active arms of the PRISMS (Prevention of Relapses and Disability by Interferon beta-1a Subcutaneously in Multiple Sclerosis) study, ${ }^{7}$ and was then validated in a separate group of patients from the post-marketing Barcelona cohort. ${ }^{53}$ This new scoring system, known as the modified Rio score, ${ }^{54}$ classified patients into three risk groups for disability progression based on first-year treatment events: low risk, ie, $\leq 4$ new T2-hyperintense lesions and no relapses; medium risk, ie, $\leq 4$ new T2-hyperintense lesions and one relapse or $>4$ new T2-hyperintense lesions and no relapses; and high risk, ie, $\leq 4$ new T2-hyperintense lesions and $\geq 2$ relapses or $>4$ new T2-hyperintense lesions and one relapse. ${ }^{54}$ However, despite its excellent specificity

Table 2 Summary of studies investigating on-treatment MRI characteristics associated with response and nonresponse to IFNB in patients with multiple sclerosis

\begin{tabular}{|c|c|c|c|c|c|}
\hline Study & $\begin{array}{l}\text { Sample } \\
\text { size }\end{array}$ & $\begin{array}{l}\text { Follow-up } \\
\text { (years) }\end{array}$ & Response definition & Nonresponders & $\begin{array}{l}\text { On-treatment features } \\
\text { associated with poor response }\end{array}$ \\
\hline \multirow[t]{2}{*}{ Tomassini et $\mathrm{al}^{42}$} & 68 & 6 & $\geq 2$ relapses & $49 \%$ & Presence of gadolinium enhancement \\
\hline & & & One-point EDSS progression & $43 \%$ & Development of NABs \\
\hline Durelli et $\mathrm{al}^{43}$ & 147 & 2 & Any relapse or one-point EDSS progression & $43 \%$ & Any active MRI lesion \\
\hline Rio et $\mathrm{al}^{44}$ & 152 & 2 & One-point EDSS progression & $16 \%$ & $\geq 3$ active MRI lesions \\
\hline Prosperini et $\mathrm{al}^{45}$ & 394 & 4.5 & One-point EDSS progression & $30 \%$ & Any new T2 lesion \\
\hline \multirow[t]{2}{*}{ Freedman et $\mathrm{al}^{46}$} & 268 & 4 & Post-one year relapse rate & NA & Relapses \\
\hline & & & $\begin{array}{l}\text { Post-one year annualized rate of } \\
\text { new MRI lesions }\end{array}$ & NA & Any active MRI lesions \\
\hline Bermel et $\mathrm{al}^{47}$ & 136 & 15 & EDSS change & $32 \%$ & Presence of gadolinium enhancement \\
\hline Horakova et $\mathrm{al}^{48}$ & 217 & 6 & $\begin{array}{l}\text { Confirmed disability progression } \\
\text { or relapse score } \geq I^{*}\end{array}$ & $52 \%$ & $\geq 3$ new T2 lesions \\
\hline
\end{tabular}

Note: *Relapse score derived from combining frequency and severity of relapses.

Abbreviations: IFNB, interferon beta; EDSS, Expanded Disability Status Scale; NABs, neutralizing antibodies; MRI, magnetic resonance imaging; NA, not available. 


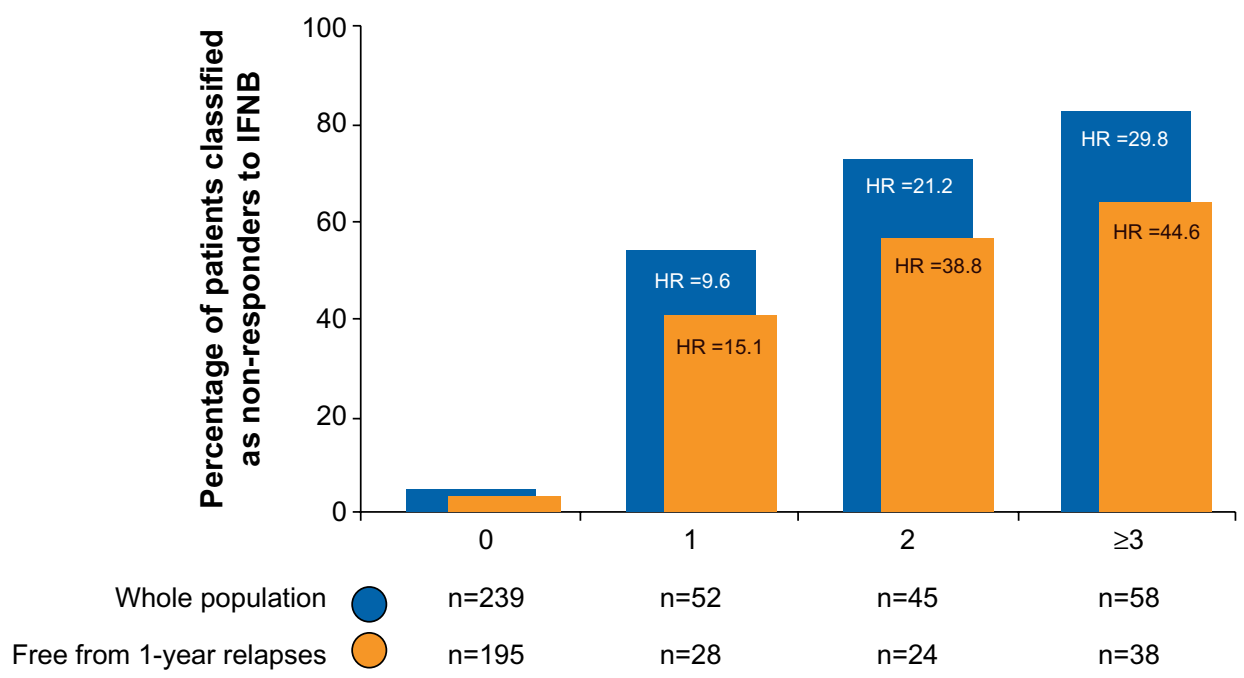

Number of new T2 lesions at 1-year MRI scan

Figure I Risk of nonresponse to IFNB over a 4.5-year follow-up according to number of new T2 lesions detected at I-year MRI scan on treatment. Note: Reprinted with permission from John Wiley and Sons. Prosperini L, Gallo V, Petsas N, et al. One-year MRI scan predicts clinical response to interferon beta in multiple sclerosis. Eur J Neurol. 2009; 16:1202-1209.45 Copyright (C) 2009 Prosperini L, et al. European Journal of Neurology @ 2009 EFNS.

Abbreviations: IFNB, interferon beta; MRI, magnetic resonance imaging; HR, hazard ratio.

$(97 \%)$, this score demonstrated very low sensitivity (24\%), implying a significant risk of misdiagnosing poor responders to IFNB.

The modified Rio score has recently been refined further, with the suggestion that a second MRI scan 6 months on from the 1-year MRI scan enables better classification of the mediumrisk group. ${ }^{24,55}$ The authors suggest that patients who relapse or accumulate two or more new T2 lesions during months 12-18 of treatment with IFNB can be classified as nonresponders. ${ }^{24,55}$

\section{Blood-derived biomarkers of response and nonresponse to IFNB}

Biological markers of responsiveness to treatment, with IFNB in particular, are landmarks of research in multiple sclerosis. According to the National Institutes of Health Biomarkers Definitions Working Group, ${ }^{58}$ a biomarker is a characteristic that is objectively measured and evaluated as an indicator of normal biological processes, pathogenic processes, or pharmacological responses to a therapeutic intervention. Biological activity can be defined as the pharmacological, physiological, and biochemical effects resulting from the interaction of a drug with its target receptor, and is a necessary but not sufficient condition for effectiveness.

Development of neutralizing antibodies (NABs) is one of the main reasons for reduction or loss of biological activity of IFNB. ${ }^{59-61}$ NABs develop in $2 \%-40 \%$ of treated patients according to the manufacturers of the product, and the majority of NAB-positive patients are identified within the first 2 years of treatment. ${ }^{62}$ The immunogenicity of IFNB is mainly influenced by the manufacturing process and the formulation, frequency of injection, route of administration (the subcutaneous route being more immunogenic than the intramuscular route) and dose used. ${ }^{63}$

Several studies have shown that the outcome for NABpositive patients, in terms of clinical and MRI disease activity and accumulation of disability, is worse than for NAB-negative patients. ${ }^{5,42,43,64-80}$ Nevertheless, it takes time before the clinical impact of NABs becomes evident, and this could help to explain why some trials did not find significant differences in clinical status between NAB-positive and NAB-negative patients (Table 3 ).

In this scenario, NAB positivity can represent a negative prognostic factor in terms of therapeutic responsiveness, and should be taken into consideration in a model integrating clinical and MRI parameters to identify poor responders early on. ${ }^{42,43}$ According to recent international guidelines, NABs should be tested in all IFNB-treated patients after the first year of treatment, and if positivity is confirmed at high titer in a subsequent test 3-6 months later, patients should be switched to a non-IFNB therapy. ${ }^{63}$

Given that IFNB binds specific receptors on human cells, ie, the interferon alpha/beta receptor, and induces a specific biochemical intracellular pathway that leads to regulation of several genes stimulated by IFNB, monitoring markers of biological activity may be a good method of evaluating the biological response to IFNB. ${ }^{81}$

Molecular markers of the biological activity of IFNB are currently being investigated at the protein 
Table 3 Impact of NABs on clinical and MRI parameters in clinical trials and observational studies

\begin{tabular}{|c|c|c|c|c|c|c|c|}
\hline \multirow[t]{2}{*}{ Study } & \multirow[t]{2}{*}{ Type of IFNB } & \multirow{2}{*}{$\begin{array}{l}\text { Percent } \\
\text { NAB-positive }\end{array}$} & \multirow{2}{*}{$\begin{array}{l}\text { Follow-up } \\
\text { (years) }\end{array}$} & \multicolumn{4}{|c|}{ Effect of NABs } \\
\hline & & & & $\mathbf{R} \mathbf{R}$ & EDSS & MRI activity & MRI BOD \\
\hline IFNB MS Study Group ${ }^{5}$ & SC IFNB-Ib & $35 \%$ & 3 & + & NS & NA & NS \\
\hline Rudick et $\mathrm{al}^{64}$ & IM IFNB-Ia & $17 \%$ & 2 & NS & NS & + & NA \\
\hline \multirow[t]{2}{*}{ Li et $\mathrm{a}^{65}$} & SC IFNB-Ia $22 \mu \mathrm{g}$ & $22 \%$ & 3 & NS & NS & NS & NS \\
\hline & SC IFNB-Ia $44 \mu \mathrm{g}$ & $15 \%$ & & & & & \\
\hline \multirow[t]{2}{*}{ Panitch et al ${ }^{66}$} & IM IFNB-Ia & $25 \%$ & 1 & NS & NA & + & NA \\
\hline & SC IFNB-Ia & $2 \%$ & & & & & \\
\hline \multirow[t]{2}{*}{ Durelli et a $\left.\right|^{67}$} & IM IFNB-Ia & $7 \%$ & 2 & NS & NA & NA & NA \\
\hline & SC IFNB-Ib & $30 \%$ & & & & & \\
\hline Polman et a ${ }^{68}$ & SC IFNB-Ib & $28 \%$ & 3 & + & NS & NA & + \\
\hline North American Study & SC IFNB-Ib $160 \mu \mathrm{g}$ & $32 \%$ & 3 & NS & NS & NS & NS \\
\hline Group on IFNB-Ib in SPMS ${ }^{69}$ & SC IFNB-Ib $250 \mu \mathrm{g}$ & $23 \%$ & & & & & \\
\hline \multirow[t]{2}{*}{ Francis et al ${ }^{70}$} & SC IFNB-Ia $22 \mu \mathrm{g}$ & $24 \%$ & 4 & + & + & + & + \\
\hline & SC IFNB-Ia $44 \mu \mathrm{g}$ & $14 \%$ & & & & & \\
\hline \multirow[t]{2}{*}{ Kappos et $\mathrm{al}^{71}$} & SC IFNB-Ia $30 \mu \mathrm{g}$ & $2 \%$ & 4 & + & + & + & + \\
\hline & SC IFNB-Ia $60 \mu \mathrm{g}$ & $5 \%$ & & & & & \\
\hline \multirow[t]{2}{*}{ Hartung et $\mathrm{al}^{72}$} & SC IFNB-Ib & $32 \%$ & 5 & NS & NS & + & + \\
\hline & & $27 \%$ & & & & & \\
\hline Sorensen et $\mathrm{a}^{73}$ & Any IFNB & $9 \%-46 \%$ & 5 & + & NS & NA & NS \\
\hline Malucchi et $\mathrm{al}^{74}$ & Any IFNB & $17 \%$ & 3 & + & + & NA & NA \\
\hline Frank et $\mathrm{a}^{75}$ & SC IFNB-Ib & $37 \%$ & 2.5 & & & + & + \\
\hline Perini et $\mathrm{a}^{76}$ & Any IFNB & $24 \%$ & 4 & + & + & NA & NA \\
\hline Tomassini et $\mathrm{al}^{42}$ & SC IFNB-Ia & $25 \%$ & 6 & & + & NA & NA \\
\hline Boz et $\mathrm{al}^{77}$ & Any IFNB & $13 \%$ & 3 & + & NS & NA & NA \\
\hline Malucchi et $\mathrm{al}^{78}$ & Any IFNB & $12 \%$ & 3 & + & & NA & NA \\
\hline Durelli et $\mathrm{al}^{43}$ & SC IFNB-Ia & $34 \%$ & 2 & + & NS & NA & NA \\
\hline \multirow{2}{*}{ Sato et $\mathrm{al}^{79}$} & IM IFNB-Ia & $35 \%$ & 4 & + & NA & + & NA \\
\hline & SC IFNB-Ib & & & & & & \\
\hline Paolicelli et $\mathrm{al}^{80}$ & Any IFNB & $14 \%$ & 5 & + & NS & NA & NA \\
\hline
\end{tabular}

Abbreviations: MS, multiple sclerosis; IFNB, interferon beta; NABs, neutralizing antibodies; RR, relapse rate; MRI, magnetic resonance imaging; EDSS, Expanded Disability Status Scale; BOD, burden of disease; +, outcome significantly worse in NAB-positive group than in NAB-negative group; NS, not significant; NA, not available; IM, intramuscular; SC, subcutaneous.

and messenger (m)RNA levels. A large number of molecules have been proposed as IFNB biomarkers, ie, beta-2-microglobulin and neopterin, ${ }^{63}$ Myxovirus resistance protein A (MxA), ${ }^{82}$ MxA mRNA,${ }^{83}$ oligoadenylate synthetase,${ }^{84}$ tumor necrosis factor-related apoptosis inducing ligand, ${ }^{84,85}$ viperin and interferon alpha-inducible protein $27,{ }^{86} \mathrm{CC}$ chemokine ligand 2, and CXC-chemokine ligand $10 .{ }^{87}$

Of the biomarkers reflecting an in vivo response to IFNB, MxA is the best validated and its use is increasing in clinical practice. ${ }^{63,88-90} \mathrm{MxA}$ mRNA levels are inhibited in NAB-positive patients, ${ }^{91}$ and absence of MxA induction by IFNB reflects complete loss of IFNB bioactivity, as demonstrated by microarray analyses of expression of different IFNB-stimulated genes. ${ }^{88}$ The MxA mRNA level after 1 year of treatment with IFNB is predictive of relapse $;^{78}$ low levels of MxA mRNA before treatment with IFNB are reported to be associated with occurrence of relapses and contrast enhancing lesions on MRI, whereas high levels of MxA mRNA seem to be associated with a longer time to relapse and reduction of contrast enhancing lesions. ${ }^{91}$

\section{Polymorphisms and gene expression signatures associated with response and nonresponse to IFNB}

Use of MxA as a biomarker of IFNB activity has been criticized for the lack of evidence of its role in the pathogenesis of multiple sclerosis, so microarray analyses of gene expression to look for biomarkers of IFNB activity (possibly related to the pathogenesis of the disease) represent outstanding research in the field. So far, none of the genes studied fits the definition of a biomarker better than MxA, but some promising molecules are under investigation.

Some molecules, including ubiquitin specific peptidase 18 (USP18) and probably E3 ubiquitin-protein ligase, are significantly induced by IFNB and are underexpressed in patients with multiple sclerosis when compared with controls, suggesting that they have a possible role in the pathogenesis of 
multiple sclerosis. ${ }^{92}$ In addition, two USP 18 haplotypes have been significantly associated with multiple sclerosis: $C G$ carriers are characterized by lower USP 18 gene expression levels in peripheral blood mononuclear cells and more clinical disease activity, whereas AA homozygosity for the intronic polymorphism $r s 2542109$ is associated with the responder phenotype in IFNB-treated patients, independent of USP18 expression levels induced by IFNB. ${ }^{93}$

Two recent interesting studies have analyzed the relationship between different IFNB-stimulated genes discovered by microarray profiles. ${ }^{94,95}$ The first combined the results of the main studies of gene profiling in response to treatment with IFNB and identified common differential expression patterns over time in peripheral blood mononuclear cells exposed to IFNB. ${ }^{94}$ The majority of the IFNB-responsive gene products were found to be involved in immune modulation or response, and linked with each other in a network, indicating that they also relate to each other at a functional level. Important regulators, such as interleukin-8, signal transducers and activators of transcription 1, Toll-like receptor 7, CC-chemokine ligand 2, and CXC-chemokine ligand 10, appear to be central nodes in the network with mutual connections to each other. Most of these genes are induced in response to treatment with IFNB. The only two genes that are consistently downregulated are interleukin-8 and $F_{c}$ fragment of immunoglobulin (Ig)E, high affinity I, receptor for; alpha polypeptide. ${ }^{94}$

These changes may not only be directly induced by the drug, but may also result from long-term continuous adaptation of the immune system to treatment over time. Most of the genes respond early to treatment, ie, within the first 24 hours. However, there are a few genes for which modulation has been observed after the first month of treatment. Monitoring expression patterns after 1 or 3 months shows both direct IFNB activity and adaptive immune changes.

It can be postulated that the following scenarios are important for predicting the effectiveness of therapy: the condition of the patient before treatment and adaptive changes during therapy, eg, certain human leukocyte antigen alleles, or single nucleotide polymorphisms in the interferon alpha/beta receptor, large multifunctional peptidase 7 , cathepsin-S, or Myxovirus (influenza virus) resistance 1; the expression level of IFNB-responsive genes at baseline; and the induction/reduction of certain genes 24 hours after administration of IFNB. ${ }^{94}$

Another study investigated the IFNB pleiotropic mechanisms of action by combining IFNB-1b-induced gene expression profiles and their biological knowledge bases. ${ }^{95}$ Genes involved in immune regulation, metabolism of mitochondrial fatty acids, and antioxidant activity have been discovered, including nuclear factor (erythroid-derived 2)-like 2 and obg-like adenosine triphosphatase 1, two molecules involved in neuronal protection and antioxidant activity, as well as the antioxidant gene nicotinamide adenine dinucleotide dehydrogenase 6, implicated in optic neuropathy and multiple sclerosis-like lesions. ${ }^{95}$

In conclusion, gene profiling studies have demonstrated a wide range of genes regulated by IFNB treatment. These discoveries highlighted the importance of different patterns of gene expression in the short-term and long-term as adaptation to therapy. In particular, overexpression of type I IFN-responsive genes has been associated with a decreased biological and clinical response to IFNB in patients with multiple sclerosis. ${ }^{88,96}$

\section{Conclusion}

Identification of responders and nonresponders to IFNB is still a challenge for neurologists. A standardized definition of response/nonresponse to IFNB is still lacking, thereby making it difficult to identify predictors/markers of a therapeutic response. While clinical features are not considered to be useful, MRI changes during treatment with IFNB are regarded as an accurate marker of treatment response, even if MRI activity occurs in the absence of clinical activity. In addition, use of blood biomarkers such as NABs and MxA could improve the sensitivity and accuracy of early recognition of responders and nonresponders to IFNB. In the near future, microarray analyses of gene expression will expand our knowledge regarding the mechanisms of action of IFNB, and could define a pattern of biological markers to predict the response to IFNB therapy.

\section{Disclosure}

LP has received consulting fees, lecture fees, and/or travel grants from Bayer Schering, Biogen Idec, Merck Serono, Novartis, and Teva. MC has received consulting fees, lecture fees, and/or travel grants from Bayer Schering, Biogen Idec, Merck Serono, Novartis, Sanofi-Aventis, and Teva. CG has no conflicts of interest to report.

\section{References}

1. Noseworthy JH, Lucchinetti C, Rodriguez M, et al. Multiple sclerosis N Engl J Med. 2000;343:938-952.

2. Wallin MT, Page WF, Kurtzke JF. Multiple sclerosis in US veterans of the Vietnam era and later military service: race, sex, and geography. Ann Neurol. 2004;55:65-71.

3. Noseworthy JH. Therapeutics of multiple sclerosis. Clin Neuropharmacol. 1991;14:49-61.

4. Freedman MS. 'Time is brain' also in multiple sclerosis. Mult Scler. 2009;15:1133-1134. 
5. The IFN Beta Study Group. Interferon beta-1b is effective in relapsingremitting multiple sclerosis. Clinical results of a multicenter, randomized, double-blind, placebo-controlled trial. Neurology. 1993;43: 655-661.

6. Jacobs LD, Cookfair DL, Rudick RA, et al. Intramuscular interferon beta-1a for disease progression in relapsing multiple sclerosis. The Multiple Sclerosis Collaborative Research Group (MSCRG). Ann Neurol. 1996;39:285-294.

7. [No authors listed]. Randomised double-blind placebo-controlled study of interferon beta-1a in relapsing-remitting multiple sclerosis. PRISMS (Prevention of Relapses and Disability by Interferon beta-1a Subcutaneously in Multiple Sclerosis) Study Group. Lancet. 1998;352:1498-1504.

8. Paty DW, Li DK. Interferon beta-1b is effective in relapsing-remitting multiple sclerosis. II. MRI analysis results of a multicenter, randomized, double-blind, placebo-controlled trial. UBC MS/MRI Study Group and the IFN Beta Multiple Sclerosis Study Group. Neurology. 1993;43:662-667.

9. Simon JH, Jacobs LD, Campion M, et al. Magnetic resonance studies of intramuscular interferon beta-1a for relapsing multiple sclerosis. The Multiple Sclerosis Collaborative research Group. Ann Neurol. 1998;43: 79-87.

10. Li DK, Paty DW. Magnetic Resonance Imaging results of the PRISMS trial: a randomized, double-blind, placebo-controlled study of interferon beta-1a in relapsing-remitting multiple sclerosis. Prevention of Relapses and Disability by Interferon beta-1a Subcutaneously in Multiple Sclerosis. Ann Neurol. 1999;42:197-206.

11. Bermel RA, Weinstock-Guttman B, Bourdette D, Foulds P, You X, Rudick RA. Intramuscular interferon beta-1a therapy in patients with relapsing-remitting multiple sclerosis: a 15-year follow-up study. Mult Scler. 2010;16:588-596.

12. Uitdehaag B, Constantinescu C, Cornelisse $\mathrm{P}$, et al. Impact of exposure to interferon beta-1a on outcomes in patients with relapsing-remitting multiple sclerosis: exploratory analyses from the PRISMS long-term follow-up study. Ther Adv Neurol Disord. 2011;4:3-14.

13. Lacy M, Hauser M, Pliskin N, Assuras S, Valentine MO, Reder A. The effects of long-term interferon- beta-1b treatment on cognitive functioning in multiple sclerosis: a 16-year longitudinal study. Mult Scler. 2013;19:1765-1772.

14. Paolillo A, Pozzilli C, Giugni E, et al. A 6-year clinical and MRI follow-up study of patients with relapsing-remitting multiple sclerosis treated with interferon-beta. Eur J Neurol. 2002;9:645-655.

15. Río J, Tintoré $\mathrm{M}$, Nos $\mathrm{C}$, et al. Interferon beta in relapsing-remitting multiple sclerosis. An eight years experience in a specialist multiple sclerosis centre. J Neurol. 2005;252:795-800.

16. Trojano M, Pellegrini F, Fuiani A, et al. New natural history of interferon-beta-treated relapsing multiple sclerosis. Ann Neurol. 2007;61: 300-306.

17. Goodin DS, Reder AT, Ebers GC, et al. Survival in MS: a randomized cohort study 21 years after the start of the pivotal IFNB-1b trial. Neurology. 2012;78:1315-1322.

18. Jacobs LD, Beck RW, Simon JH, et al. Intramuscular interferon beta-1a therapy initiated during a first demyelinating event in multiple sclerosis. N Engl J Med. 2000;343:898-904.

19. Comi G, Filippi M, Barkhof F, et al. Effect of early interferon treatment on conversion to definite multiple sclerosis: a randomised study. Lancet. 2001;357:1576-1582.

20. Kappos L, Polman CH, Freedman MS, et al. Treatment with interferon beta-1b delays conversion to clinically definite and McDonald MS in patients with clinically isolated syndrome. Neurology. 2006;67: 1242-1249.

21. Comi G, De Stefano N, Freedman MS, et al. Comparison of two dosing frequencies of subcutaneous interferon beta-1a in patients with a first clinical demyelinating event suggestive of multiple sclerosis (REFLEX): a phase 3 randomised controlled trial. Lancet Neurol. 2012;11:33-41.
22. Rudick RA, Polman CH. Current approaches to the identification and management of breakthrough disease in patients with multiple sclerosis. Lancet Neurol. 2009;8:545-559.

23. Naismith RT. Multiple sclerosis therapeutic strategies: start safe and effective, reassess early, and escalate if necessary. Neurol Clin Pract. 2011;1:69-71.

24. Sormani MP, De Stefano N. Defining and scoring response to IFNB in multiple sclerosis. Nat Rev Neurol. 2013;9:504-512.

25. Pozzilli C, Prosperini L. Clinical markers of therapeutic response to disease modifying drugs. Neurol Sci. 2008;29 Suppl 2:S211-S213.

26. Rio J, Nos C, Tintoré $\mathrm{M}$, et al. Defining the response to interferon beta in relapsing-remitting multiple sclerosis patients. Ann Neurol. 2006;59: 344-352.

27. Kurtzke JF. Rating neurological impairment in Multiple Sclerosis: an expanded disability status scale (EDSS). Neurology. 1983;33: 1444-1452.

28. Cutter GR, Baier ML, Rudick RA, et al. Development of a multiple sclerosis functional composite as a clinical trial outcome measure. Brain. 1999;122:871-882.

29. Río J, Nos C, Tintoré M, et al. Assessment of different treatment failure criteria in a cohort of relapsing-remitting multiple sclerosis patients treated with interferon beta: implications for clinical trials. Ann Neurol. 2002;52:400-406.

30. Roullet E, Dominique P, Le Canuet P, et al. Application of different criteria for clinical response to beta-interferon in relapsing-remitting multiple sclerosis. Neurology. 2003;60 Supp1 1:A168.

31. Waubant E, Vukusic S, Gignoux L, et al. Clinical characteristics of responders to interferon therapy for relapsing MS. Neurology. 2003;61: 184-189.

32. Trojano M, Liguori M, Paolicelli D, et al. Southern Italy MS Group. Interferon beta in relapsing-remitting multiple sclerosis: an independent postmarketing study in southern Italy. Mult Scler. 2003;9:451-457.

33. Coppola G, Lanzillo R, Florio C, et al. Long-term clinical experience with weekly interferon beta-1a in relapsing multiple sclerosis. Eur $J$ Neurol. 2006;13:1014-1021.

34. Portaccio E, Zipoli V, Siracusa G, et al. Response to interferon-beta therapy in relapsing-remitting multiple sclerosis: a comparison of different clinical criteria. Mult Scler. 2006;12:281-286.

35. O'Rourke K, Walsh C, Antonelli G, et al. Predicting beta-interferon failure in relapsing-remitting multiple sclerosis. Mult Scler. 2007;13: 336-342.

36. Fromont A, Debouverie M, Le Teuff G, et al. Clinical parameters to predict response to interferon in relapsing multiple sclerosis. Neuroepidemiology. 2008;31:150-156.

37. Goodin D, Traboulsee A, Knappertz V, et al. Relationship between early clinical characteristics and long term disability outcomes: 16 year cohort study (follow-up) of the pivotal interferon beta-1b trial in multiple sclerosis. J Neurol Neurosurg Psychiatry. 2012;83:282-287.

38. Mezei Z, Bereczki D, Racz L, et al. Can a physician predict the clinical response to first-line immunomodulatory treatment in relapsingremitting multiple sclerosis? Neuropsychiatr Dis Treat. 2012;8: 465-473.

39. Miller DH, Grossman R, Reingold S, et al. The role of magnetic resonance techniques in understanding and managing multiple sclerosis. Brain. 1998;121:3-24.

40. Yong VW, Chabot S, Stuve O, Williams G. Interferon beta in the treatment of multiple sclerosis: mechanisms of action. Neurology. 1998;51:682-689.

41. Rudick RA, Lee JC, Simon J, et al. Defining interferon beta response status in multiple sclerosis patients. Ann Neurol. 2004;56:548-555.

42. Tomassini V, Paolillo A, Russo P, et al. Predictors of long-term clinical response to interferon beta therapy in relapsing multiple sclerosis. J Neurol. 2006;253:287-293.

43. Durelli L, Berbero P, Bergui M, et al. MRI activity and neutralizing antibody as predictor of response to IFNB treatment in MS. J Neurol Neurosurg Psychiatry. 2008;79:646-651. 
44. Rio J, Rovira A, Tintoré M, et al. Relationship between MRI lesion activity and response to IFN-beta in relapsing-remitting multiple sclerosis patients. Mult Scler. 2008;14:479-484.

45. Prosperini L, Gallo V, Petsas N, et al. One-year MRI scan predicts clinical response to interferon beta in multiple sclerosis. Eur J Neurol. 2009; 16:1202-1209.

46. Freedman M, Hartung HP, Miller D, et al. Predictors of disease activity in CIS patients treated with IFNB-1b in the BENEFIT study. Mult Scler. 2011;17 Suppl 10:S16/O31.

47. Bermel RA, You X, Foulds P, et al. Predictors of long-term outcome in multiple sclerosis patients treated with interferon beta. Ann Neurol. 2013;73:95-103.

48. Horakova D, Kalincik T, Dolezal O, et al. Early predictors of nonresponse to interferon in multiple sclerosis. Acta Neurol Scand. 2012;126:390-397.

49. Sormani MP, Bonzano L, Roccatagliata L, et al. Magnetic resonance imaging as a potential surrogate for relapses in multiple sclerosis: a meta-analytic approach. Ann Neurol. 2009;65:268-275.

50. Sormani MP, Stubinski B, Cornelisse P, et al. Magnetic resonance active lesions as individual-level surrogate for relapses in multiple sclerosis Mult Scler. 2011;17:541-549.

51. Sormani MP, Bruzzi P. MRI lesions as a surrogate for relapses in multiple sclerosis: a meta-analysis of randomised trials. Lancet Neurol. 2013;12:669-676.

52. Prosperini L, Mancinelli CR, De Giglio L, et al. Interferon-beta failure predicted by EMA criteria or isolated MRI activity in multiple sclerosis. Mult Scler. September 3, 2013. [Epub ahead of print.]

53. Rio J, Castilló J, Rovira A, et al. Measures in the first year of therapy predict the response to interferon beta in MS. Mult Scler. 2009;15: 848-853.

54. Sormani M, Rio J, Tintorè M, et al. Scoring treatment response in patients with relapsing multiple sclerosis. Mult Scler. 2013;19:605-612.

55. Sormani M, Signori A, Stromillo M, De Stefano N. Refining response to treatment as defined by the Modified Rio Score. Mult Scler. 2013;19: 1246-1247.

56. Sormani MP, Li DK, Bruzzi P, et al. Combined MRI lesions and relapses as a surrogate for disability in multiple sclerosis. Neurology. 2011;77:1684-1690

57. Freedman MS, Selchen D, Arnold DL, et al. Treatment optimization in MS: Canadian MS Working Group Updated Recommendations. Can J Neurol Sci. 2013;40:307-323.

58. Biomarkers Definition Working Group. Biomarkers and surrogate endpoints: preferred definitions and conceptual framework. Clin Pharmacol Ther. 2001;69:89-95.

59. Creeke PI, Farrell RA. Clinical testing for neutralizing antibodies to interferon-beta in multiple sclerosis. Ther Adv Neurol Disord. 2013;6:3-17.

60. Malucchi S, Gilli F, Caldano M, et al. One-year evaluation of factors affecting the biological activity of interferon beta in multiple sclerosis patients. J Neurol. 2011;258:895-903.

61. Deisenhammer F, Reindel M, Harvey J, Gasse T, Dilitz E, Berger T. Bioavailability of interferon beta $1 \mathrm{~b}$ in MS patients with and without neutralizing antibodies. Neurology. 1999;52:1239-1243.

62. Sorensen PS, Koch-Henriksen N, Ross C, et al. Appearance and disappearance of neutralizing antibodies during interferon-beta therapy. Neurology. 2005;65:33-39.

63. Polman CH, Bertolotto A, Deisenhammer F, et al. Recommendations for clinical use of data on neutralizing antibodies to interferon-beta therapy in multiple sclerosis. Lancet Neurol. 2010;9:740-750.

64. Rudick RA, Simonian NA, Alam JA, et al. Incidence and significance of neutalizing antibodies to interferon beta 1a in multiple sclerosis. Neurology. 1998;50:1266-1272.

65. Li DK, Zhao MD, Paty DW; University of British Columbia MS/MRI Analysis Group. The SPRECTRIMS Study Group. Randomized controlled trial of interferon-beta 1a in secondary progressive MS. MRI results. Neurology. 2001;56:1505-1513.
66. Panitch H, Goodin DS, Francis G, et al; for the EVIDENCE (Evidence of Interferon Dose-Response: European North American Comparative Efficacy) Study Group and the University of British Columbia MS/MRI Research Group. Randomized, comparative study of interferon $\beta$-1a treatment regimens in MS. The EVIDENCE Trial. Neurology. 2002;59:1496-1506.

67. Durelli L, Verdun E, Barbero P, et al; and the Independent Comparison of Interferon (INCOMIN) Trial Study Group. Every-other-day interferon beta-1b versus once-weekly interferon beta-1a for multiple sclerosis: results of a 2-year prospective randomised multicentre study (INCOMIN). Lancet. 2002;359:1453-1460.

68. Polman C, Kappos L, White R, et al. Neutralizing antibodies during treatment of secondary progressive MS with interferon beta-1b. Neurology. 2003;60:37-43.

69. Panitch H, Miller A, Paty D, Weinshenker B; The North American Study Group on Interferon beta-1b in Secondary Progressive MS. Interferon beta-1b in secondary progressive MS. Results from a 3-year controlled study. Neurology. 2004;3:1788-1795.

70. Francis GS, Rice GP, Alsop JC, et al. Interferon beta-1a in MS: results following development of neutralizing antibodies in PRISMS Neurology. 2005;65:48-55.

71. Kappos L, Clanet M, Sandberg W, et al. Neutralizing antibodies and efficacy of interferon $\beta$-1a: a 4 year controlled study. Neurology. 2005;65:40-47.

72. Hartung HP, Freedman MF, Polman CH, et al; for the BENEFIT Study Group. Interferon beta-1b-neutralizing antibodies 5 years after clinically isolated syndrome. Neurology. 2011;77:835-843.

73. Sorensen PS, Ross C, Clemmensen KM, et al; The Danish Multiple Sclerosis Study Group. Clinical importance of neutralizing antibodies against interferon beta in patients with relapsing-remitting multiple sclerosis. Lancet. 2003;362:1184-1191.

74. Malucchi S, Sala A, Gilli F, et al. Neutralizing antibodies reduce the efficacy of beta IFNB during treatment of multiple sclerosis. Neurology. 2004;62:2031-2037.

75. Frank JA, Richert N, Bash C, et al. Interferon beta-1b slows progression of atrophy in RRMS. Three-year follow-up in Nab+ and Nab- patients. Neurology. 2004;62:719-725.

76. Perini P, Calabrese M, Biasi G, Gallo P. The clinical impact of interferon beta antibodies in relapsing-remitting MS. J Neurol. 2004;251 305-309.

77. Boz C, Oger J, Gibbs E, et al. Reduced effectiveness of long-term interferon-treatment on relapses in neutralizing antibody-positive multiple sclerosis patients: a Canadian multiple sclerosis clinic-based study. Mult Scler. 2007;13:1127-1137.

78. Malucchi S, Gilli F, Caldano M, et al. Predictive markers for response to interferon therapy in patients with multiple sclerosis. Neurology. 2008;70:119-127.

79. Sato DK, Nakashima I, Fukazawa T, et al. Neutralizing antibodies are associated with a reduction of interferon-b efficacy during the treatment of Japanese multiple sclerosis patients. Tohoku J Exp Med. 2012;228: 85-92.

80. Paolicelli D, D’Onghia M, Pellegrini F, et al. The impact of neutralizing antibodies on the risk of disease worsening in interferon b-treated relapsing multiple sclerosis: a 5 year post-marketing study. J Neurol. 2013;260:1562-1568.

81. Gilli F, Valentino P, Caldano M, et al. Expression and regulation of IFN alpha/beta receptor in IFNB-treated patients with multiple sclerosis. Neurology. 2008;71:1940-1947.

82. Bertolotto A, Gilli F, Sala A, et al. Evaluation of bioavailability of three types of IFN beta in multiple sclerosis patients by a new quantitativecompetitive-PCR method for MxA quantification. J Immunol Methods. 2001;256:141-152.

83. Pachner A, Narayan K, Price N, et al. MxA gene expression analysis as an interferon-beta bioactivity measurement in patients with multiple sclerosis and the identification of antibody-mediated decreased bioactivity. Mol Diagn. 2003;7:17-25. 
84. Wandinger KP, Lünemann JD, Wengert O, et al. TNF-related apoptosis inducing ligand (TRAIL) as a potential response marker for interferonbeta treatment in multiple sclerosis. Lancet. 2003;361:2036-2043.

85. Gilli F, Marnetto F, Caldano M, et al. Biological markers of IFN beta therapy: comparison among interferon-stimulated-genes MxA, TRAIL, and XAF-1. Mult Scler. 2006;12:1-11.

86. Pachner AR, Warth JD, Pace A, et al. Effect of neutralizing antibodies on biomarker responses to interferon beta. The INSIGHT study. Neurology. 2009;73:1493-1500.

87. Sellebjerg F, Krakauer M, Hesse D, et al. Identification of new sensitive biomarkers for the in vivo response to interferon-beta treatment in multiple sclerosis using DNA-array evaluation. Eur J Neurol. 2009;16: 1291-1298.

88. Hesse D, Sellbjerg F, Sorensen PS. Absence of MxA induction by interferon $\beta$ in patients with MS reflects complete loss of bioactivity. Neurology. 2009;73:372-377.

89. Zanotti C, Ghidini C, Lamorgese C, Caimi L, Capra R, Imberti L. Transfer of myxovirus-protein-A mRNA assay for interferon-beta bioactivity measurement in multiple sclerosis patients to routine laboratory practice. A 4-year experience. Clin Chem Lab Med. 2010;48:1235-1238.

90. Bertolotto A, Gilli F, Sala A, et al. Persistent neutralizing antibodies abolish the interferon beta bioavailability in MS patients. Neurology. 2003;60:634-639.
91. Van der Voort LF, Vennegoor A, Visser A, et al. Spontaneous MxA mRNA level predicts relapses in patients with recently diagnosed MS. Neurology. 2010;75:1228-1233.

92. Malhotra S, Bustamante MF, Pérez-Miralles F, et al. Search for specific biomarkers of IFN $\beta$ bioactivity in patients with multiple sclerosis. PLoS One. 2011;6:e23634.

93. Malhotra S, Morcillo-Suarez C, Nurtdinova S, et al. Roles of the ubiquitin peptidase USP18 in multiple sclerosis and the response to interferon-b treatment. Eur J Neurol. 2013;20:1390-1397.

94. Paap BK, Hundeshagen A, Hecker M, Zettl UK. An inventory of short term and long term changes in gene expression under interferon treatment of relapsing remitting MS patients. Curr Pharm Design. 2012;18:4475-4484.

95. Croze E, Yamaguchi KD, Knappertz V, et al. Interferon-beta-1binduced short- and long-term signatures of treatment activity in multiple sclerosis. Pharmacogenomics J. 2013;13:443-451.

96. Comabella M, Lunemann JD, Rio J, et al. A type 1 interferon signature in monocytes is associated with poor response to interferon-beta in multiple sclerosis. Brain. 2009;132:3353-3365.
Degenerative Neurological and Neuromuscular Disease

\section{Publish your work in this journal}

Degenerative Neurological and Neuromuscular Disease is an international, peer-reviewed, open access journal focusing on research into degenerative neurological and neuromuscular disease, identification of therapeutic targets and the optimal use of preventative and integrated treatment interventions to achieve improved outcomes, enhanced

\section{Dovepress}

survival and quality of life for the patient. The manuscript management system is completely online and includes a very quick and fair peer-review system. Visit http://www.dovepress.com/testimonials.php to read real quotes from published authors. 